\title{
Intuitive Participation in Aggressive Intergroup Conflict: Evidence of Weak Versus Strong Parochial Altruism
}

\author{
Robert Böhm * \\ Decision Analysis, School of Business and Economics, RWTH Aachen University, Aachen, Germany
}

Keywords: intergroup conflict, parochial altruism, dual systems decision making, team games, ego depletion

\section{A commentary on}

In intergroup conflict, self-sacrifice is stronger among pro-social individuals, and parochial altruism emerges especially among cognitively taxed individuals

by De Dreu, C. K. W., Dussel, D. B., and Ten Velden, F. S. (2015). Front. Psychol. 6:572. doi: 10.3389/fpsyg.2015.00572

Humans are unusually cooperative and prosocial, sharing resources with kin and non-kin others. At the same time, they engage in violent intergroup conflict and discriminate against members of other groups. How can we explain this apparent inconsistency? Building on Darwin (1871), it has been proposed that self-sacrificing prosociality toward the in-group and hostility toward the out-group may have co-evolved (Choi and Bowles, 2007; García and van den Bergh, 2011). Research on so-called parochial altruism, i.e., the motivation to benefit ingroup members at personal cost, while not benefitting or even harming out-group members, recently received much attention in psychology and beyond (for reviews see, De Dreu et al., 2014; Rusch, 2014; Yamagishi and Mifune, 2016). Empirical studies aiming to support the parochial altruism hypothesis yielded mixed results, though. For instance, whereas some studies provided support for the parochial altruism hypothesis (e.g., Bernhard et al., 2006; Abbink et al., 2012), others failed to show a relationship between individual-level prosociality and intergroup discrimination (e.g., Corr et al., 2015). And yet others found that prosocial individuals are less likely to discriminate against out-group members (e.g., Thielmann and Böhm, in press).

De Dreu et al. (2015) provide a novel perspective to this debate by showing that parochial altruistic behavior increases in intuitive compared to deliberative decision making. The paper is among the first to combine research on intuitive vs. deliberative decision making (e.g., Rand et al., 2012, 2014; Bear and Rand, 2016) with research on the participation in destructive intergroup conflict (e.g., Bornstein, 2003; Choi and Bowles, 2007; Rusch, 2014). In detail, the authors used an easy vs. difficult Stroop Interference Task (Stroop, 1935) to manipulate cognitive self-control prior to an intergroup conflict game. In this game-the Intergroup Prisoner's Dilemma-Maximizing Difference (IPD-MD; Halevy et al., 2008) - participants could decide between selfishly keeping their endowment or contributing it to one (or both) of two public goods. Either they contributed to a within-group pool that benefits their in-group without affecting the out-group. Alternatively, they could have also contributed to a between-group pool that equally benefits the in-group as the within-group pool, but additionally harms the out-group. Because the between-group pool decreases the outcome of the out-group absolutely and relatively to the other options available, contributions to this pool can be interpreted as parochial altruism. Although the contributions 
to the between-group pool were generally low as in previous research (e.g., Halevy et al., 2008, 2012; De Dreu et al., 2010; Weisel, 2015; Weisel and Böhm, 2015), De Dreu et al. (2015) found that they increased when participants were cognitively taxed. This effect was independent of participants' social value orientation, i.e., their general preference for the welfare of others (Van Lange and Kuhlman, 1994; for an overview see, Murphy and Ackermann, 2014). The findings imply that parochial altruism might be more strongly pronounced when individual self-control is low. Furthermore, they can be interpreted as support of the claim that prosociality toward the in-group and parochialism toward the out-group may have co-evolved. In particular, one could argue that intuitive behavioral tendencies of benefitting ingroup members while-at the same time-harming out-group members are based on adaptive evolutionary processes, but are inhibited because modern intergroup relations are less violent (Pinker, 2011). The study might therefore be the starting point of a novel research program combining (different) manipulations of intuitive vs. deliberative decision making with intergroup social dilemmas.

The insights of De Dreu et al. (2015) contribute to the recent debate on the specific circumstances under which people do (not) show parochial altruistic behavior, as apparent from the numerous papers that appeared in the Frontiers Research Topic Parochial altruism: Pitfalls and prospects (Rusch et al., 2016). Here, I would like to point to a conceptual ambiguity that may have important consequences for the interpretation of the findings by De Dreu et al. (2015) and others: In the IPD-MD it is not only the absolute amount but also-and in particular-the relative amount of tokens contributed to the between-group pool compared with the within-group pool that is crucial for the interpretation. In detail, a larger contribution to the between-group pool relative to the within-group pool may be interpreted as negative attitude toward the out-group, an equal contribution to both pools as indifference regarding the out-group's welfare, and a smaller

\section{REFERENCES}

Abbink, K., Brandts, J., Herrmann, B., and Orzen, H. (2012). Parochial altruism in inter-group conflicts. Econ. Lett. 117, 45-48. doi: 10.1016/j.econlet.2012.04.083

Bear, A., and Rand, D. G. (2016). Intuition, deliberation, and the evolution of cooperation. Proc. Natl. Acad. Sci.U.S.A. 113, 936-941. doi: 10.1073/pnas.15177 80113

Bernhard, H., Fischbacher, U., and Fehr, E. (2006). Parochial altruism in humans. Nature 442, 912-915. doi: 10.1038/nature04981

Bornstein, G. (2003). Intergroup conflict: individual, group, and collective interests. Pers. Soc. Psychol. Rev. 7, 129-145. doi: 10.1207/S15327957PSPR 0702_129-145

Choi, J.-K., and Bowles, S. (2007). The coevolution of parochial altruism and war. Science 318, 636-640. doi: 10.1126/science.1144237

Corr, P. J., Hargreaves Heap, S. P., Seger, C. R., and Tsutsui, K. (2015). An experiment on individual "parochial altruism" revealing no connection between individual "altruism" and individual "parochialism." Front. Psychol. 6:1261. doi: 10.3389/fpsyg.2015.01261

Darwin, C. (1871). The Descent of Man, and Selection in Relation to Sex. London: John Murray. contribution to the between-group pool as positive attitude toward the out-group. Importantly, although De Dreu et al. (2015) show differences in contributions to the between-group pool between experimental conditions, the contributions to the within-group pool are always exceeding those to the betweengroup pool. As such, their findings indicate that in the high taxing condition, the attitude (and the behavior resulting from it) toward the out-group is less positive rather than more negative compared to the low taxing condition. And indeed, both effects are consistent with the interpretation of increased parochial altruism given the definition provided above ("[...] not benefitting or even harming members of other groups [...]"; italics added). Therefore, in order to increase the conceptual clarity of in-group-bounded prosociality, I propose a semantic differentiation between effects that are based on a lack of positive attitudes toward the out-group, i.e., weak parochial altruism, and effects that are due to negative attitudes toward the out-group, i.e., strong parochial altruism. Although the attitudes toward the out-group are on a positive-negative continuum, I suggest that the resulting discriminatory behaviors constitute different psychological qualities and, furthermore, that the transition from weak to strong parochial altruism might follow specific requirements and processes. Future research should show the joint and differential predictors of weak vs. strong parochial altruism, e.g., by classifying participants into different types (i.e., weak vs. strong parochial altruists) based on their relative contribution behavior. Combining novel tests on mediating and moderating factors as well as a more finegrained conceptualization of parochial altruism effects itself could eventually advance our understanding of intergroup conflict in general.

\section{AUTHOR CONTRIBUTIONS}

The author confirms being the sole contributor of this work and approved it for publication.

De Dreu, C. K. W., Balliet, D., and Halevy, N. (2014). Chapter one - parochial cooperation in humans: forms and functions of self-sacrifice in intergroup conflict. Adv. Motiv. Sci. 1, 1-47. doi: 10.1016/bs.adms.2014.08.001

De Dreu, C. K. W., Greer, L. L., Handgraaf, M. J. J., Shalvi, S., Van Kleef, G. A., Baas, M., et al. (2010). The neuropeptide oxytocin regulates parochial altruism in intergroup conflict among humans. Science 328, 1408-1411. doi: 10.1126/science.1189047

De Dreu, C. K. W., Dussel, D. B., and Ten Velden, F. S. (2015). In intergroup conflict, self-sacrifice is stronger among pro-social individuals, and parochial altruism emerges especially among cognitively taxed individuals. Front. Psychol. 6:572. doi: 10.3389/fpsyg.2015.00572

García, J., and van den Bergh, J. C. J. M. (2011). Evolution of parochial altruism by multilevel selection. Evol. Hum. Behav. 32, 277-287. doi: 10.1016/j.evolhumbehav.2010.07.007

Halevy, N., Bornstein, G., and Sagiv, L. (2008). "In-group love" and "out-group hate" as motives for individual participation in intergroup conflict: a new game paradigm. Psychol. Sci. 19, 405-411. doi: 10.1111/j.1467-9280.2008.02100.x

Halevy, N., Weisel, O., and Bornstein, G. (2012). "In-group love” and "Out-group hate" in repeated interaction between groups. J. Behav. Decis. Mak. 25, 188-195. doi: $10.1002 / b d m .726$ 
Murphy, R. O., and Ackermann, K. A. (2014). Social value orientation: theoretical and measurement issues in the study of social preferences. Pers. Soc. Psychol. Rev. 18, 13-41. doi: 10.1177/1088868313501745

Pinker, S. (2011). The Better Angels of Our Nature: Why Violence Has Declined. New York, NY: Viking.

Rand, D. G., Greene, J. D., and Nowak, M. A. (2012). Spontaneous giving and calculated greed. Nature 489, 427-430. doi: 10.1038/nature 11467

Rand, D. G., Peysakhovich, A., Kraft-Todd, G. T., Newman, G. E., Wurzbacher, O., Nowak, M. A., et al. (2014). Social heuristics shape intuitive cooperation. Nat. Commun. 5, 3677. doi: $10.1038 /$ ncomms 4677

Rusch, H. (2014). The evolutionary interplay of intergroup conflict and altruism in humans: A review of parochial altruism theory and prospects for its extension. Proc. R. Soc. B Biol. Sci. 281:20141539. 10.1098/rspb.2014.1539

Rusch, H., Böhm, R., and Herrmann, B. (eds.). (2016). Parochial Altruism: Pitfalls and Prospects. Lausanne: Frontiers Media.

Stroop, J. R. (1935). Studies of interference in serial verbal reactions. J. Exp. Psychol. 18, 643-662. doi: 10.1037/h0054651

Thielmann, I., and Böhm, R. (in press). Who does (not) participate in intergroup conflict? Soc. Psychol. Pers. Sci. doi: 10.1177/1948550616660160

Van Lange, P. A. M., and Kuhlman, D. M. (1994). Social value orientations and impressions of partner's honesty and intelligence: a test of the might versus morality effect. J. Pers. Soc. Psychol. 67, 126-141. doi: 10.1037/00223514.67.1.126

Weisel, O. (2015). Negative and positive externalities in intergroup conflict: exposure to the opportunity to help the outgroup reduces the inclination to harm it. Front. Psychol. 6:1594. doi: 10.3389/fpsyg.2015.01594

Weisel, O., and Böhm, R. (2015). "Ingroup love" and "outgroup hate" in intergroup conflict between natural groups. J. Exp. Soc. Psychol. 60, 110-120. doi: 10.1016/j.jesp.2015.04.008

Yamagishi, T., and Mifune, N. (2016). Parochial altruism: does it explain modern human group psychology? Curr. Opin. Psychol. 7, 39-43. doi: 10.1016/j.copsyc.2015.07.015

Conflict of Interest Statement: The author declares that the research was conducted in the absence of any commercial or financial relationships that could be construed as a potential conflict of interest.

Copyright $\odot 2016$ Böhm. This is an open-access article distributed under the terms of the Creative Commons Attribution License (CC BY). The use, distribution or reproduction in other forums is permitted, provided the original author(s) or licensor are credited and that the original publication in this journal is cited, in accordance with accepted academic practice. No use, distribution or reproduction is permitted which does not comply with these terms. 